\title{
Pembuatan Aplikasi Pengolahan Nilai Dengan MS. Excel Bagi Guru SMA Negeri 4 Pagar Alam
}

\author{
Alfis Arif \\ Program Studi Teknik Informatika; Sekolah Tinggi Teknologi Pagaralam (STTP) \\ Jl. M. Siagim No.75 Kel. Karang Dalo, Dempo Tengah, Kota Pagar Alam \\ Telp/Fax: (0730) 621916 \\ e-mail: alfisarif@yahoo.com.
}

\begin{abstract}
Abstrak
Guru SMAN 4 Kota Pagaralam mengelola dan mengolah nilai siswa saat ini kebanyakan dilakukan secara manual dihitung satu per satu di jumlah maka nanti diperoleh nilai siswa, hal ini dilakukan terutama oleh Guru yang senior dan latar belakang keilmuan yang tidak ada teknologinya seperti pelajaran-pelajaran ilmu sosial, hal ini membuat pekerjaan mengolah nilai menjadi tidak efisien karena cukup memakan waktu yang lama, sehingga civitas STTP memandang perlu untuk melakukan pengabdian dengan melatih para Guru membuat aplikasi pengolah data nilai dengan menggunakan MS. Excel. Pelatihan yang dilakukan menggunakan metode ceramah dilanjutkan dengan praktek mengolah data nilai, agar pelaksanaan pelatihan berjalan dengan baik maka sebelum pelatihan dilakukan terlebih dahulu tes untuk mengetahui pemahaman Guru terhadap pengolahan data menggunakan excel dan hasilnya para Guru tidak biasa menggunakan excel, sehingga pelatihan menjadi sangat penting. Setelah pelatihan kembali dilakukan tes untuk mengetahui sejauh mana efektifitas pelaksanaan pelatihan dan hasilnya Para peserta mampu melakukan perhitungan dan pengolahan data menggunakan aplikasi excel seluruh peserta, artinya pelatihan yang dilakukan berdasarkan tes ini berhasil dilakukan.
\end{abstract}

Kata kunci-Guru, Siswa, Sosial, Excel, Peserta, Tes.

\section{PENDAHULUAN.}

Dosen dan civitas perguruan tinggi wajib melaksanakan pengabdian kepada masyarakat membantu masyarakat menyelesaikan permasalahannya dan membuat tatanan kehidupan masyarakat lebih sejahtera, maju dan makmur sehingga kehidupan menjadi nyaman dan lebih baik lagi, hal ini dilakukan sesuai dengan bidang keahlian yang dimiliki oleh civitas perguruan tingg, dalam hal STTP, maka pelaksanaan pengabdian harus sesuai dengan keilmuannya yaitu Teknologi informasi dan sistem informasi.

Saat ini perkembangan teknologi informasi dan komunikasi khususnya teknologi yang mendukung terlaksananya kegiatan pembelajaran saat ini sangat banyak dan menawarkan kemudahan sesuai ke unggulannya masing-masing, salah satunya Ms. Excel yang bisa di manfaatkan sebagai sarana pembuatan aplikasi pengolahan data nilai yang sangat baik dan banyak sekali di pergunakan. Media ini sangat banyak sekali digunakan di sebagai sarana pengolahan data yang sangat familiar, selain itu aplikasi ini murah karena sudah ter-bundle atau terpaket dalam Microsoft office yang sangat baku.

Pengaplikasian Ms. Excel sebagai media/sarana pembuatan aplikasi pengolahan data nilai ini sangat di sarankan karena memiliki menu-menu yang sesuai dengan standar penulisan yang di sarankan oleh para ahli yang sangat kompeten, sehingga pada saat penyusunan pada Ms. Excel ini pembuat aplikasi tinggal klik menu-menu yang di maksud maka akan di dapat hasil tulisan (hitungan/pengolah data) yang baik (standar), selain itu Ms. Excel merupakan software pengolah data yang include dalam software dalam sistem komputer dan biasanya benar atau merupakan software asli yang di buat oleh Microsoft sehingga tidak akan ditemui bagian menu yang rusak (crash), selain itu apa bila ingin meng-upgrade, atau mengganti ke versi terbaru Microsoft menyediakan dengan mudah. 
Dari pemaparan diatas dituntut agar para Guru Pelajaran Umum harus selalu meningkatkan kualitas pembelajaran dengan menggunakan semua resource terkait, sehingga dipandang perlu untuk diadakan pelatihan pembuatan aplikasi pengolahan data nilai ini. Berdasarkan informasi yang diperoleh dari para peserta Guru SMAN 4 Pagaralam, masalah yang dihadapi dapat diidentifikasikan sebagai berikut.

1. Para Guru belum terlalu memahami Microsoft Excel terutama bagi guru senior.

2. Para Guru belum dapat membuat aplikasi pengolah data nilai dengan baik.

\section{METODE.}

Proses kegiatan pengabdian yang dilakukan menggunakan tata cara dengan menyimak (menonton) bersama, membaca bersama (modul pelatihan), memahami tools aplikasi (Software) dan berinteraksi secara langsung (Aplikatif) dengan software. Sampai seluruh peserta memahami dengan baik materi yang disampaikan kepada peserta pelatihan pengolahan data nilai menggunakan excel ini.

\subsection{Pengabdian (PkM).}

Progran pengabdian masyarakat ialah suatu kegiatan bertujuan membantu masyarakat dalam beberapa aktivitas tanpa mengharapkan imbalan berbentuk apapun. Secara umum program ini dirancang oleh LPPM untuk memberikan kontribusi nyata bagi bangsa, khususnya di Pagar Alam, dalam mengembangkan kesejahteraan dan kemajuan bangsa dan daerah. Kegiatan Pengabdian Masyarakat salah satu bagian Tri Dharma Perguruan Tinggi. Bentuk kegiatan Pengabdian Masyarakat bisa berupa: Bakti Sosial \& Mengajar. Ada pun tujuan Pengabdian Masyarakat di Perguruan Tinggi, sebagai berikut:

1. Melaksanakan alih teknologi, ilmu, dan seni kepada masyarakat untuk pengembangan martabat manusia dan kelestarian sumber daya alam yang ada di pagar alam.

2. Menciptakan inovasi teknologi informasi untuk meningkatkan pembangunan ekonomi daerah dengan melakukan komersialisasi hasil penelitian, yang ada pada STTP;

3. Menyampaikan solusi berdasarkan hasil kajian akademik atas kebutuhan, tantangan, atau persoalan yang dihadapi masyarakat, baik secara langsung maupun tidak langsung;

4. Melaksanakan kegiatan yang dapat mengentaskan masyarakat tersisih (preferential option for the poor) pada semua strata, yaitu masyarakat yang tersisih secara ekonomi, politik, sosial, dan budaya;

\subsection{Nilai.}

Nilai merupakan sarana atau alat yang menunjukkan alasan dasar bahwa "cara pelaksanaan atau keadaan akhir tertentu lebih disukai secara sosial dibanding cara pelaksanaan atau keadaan akhir berlawanan. Nilai memuat elemen pertimbangan yang membawa ide-ide seorang individu mengenai hal-hal yang benar, baik, atau diinginkan (Wikipedia).

\subsection{Microsoft Excel.}

Microsoft excel merupakan aplikasi komputer pengolahan data yang kebanyakan berupa pengolaha perhitungan data berupa data angka, saat ini program Microsoft excel telah menyatu atau terbundel dalam Microsoft office bersama word, ppt dan lain-lain, berikut cara menjalankannya:

1. Dobel klik ikon MS EXCEL (jika ada) yang terdapat pada layar desktop komputer, atau

2. Klik ikon MS EXCEL pada MS Office Shortcut Bar (jika ada), atau

3. Melalui menu Start $\rightarrow$ Programs $\rightarrow$ Microsoft Excel, atau

4. Melalui menu Start $\rightarrow$ Run $\rightarrow$ Browse $\rightarrow$ (cari berkas Excel.exe).

\subsection{Pre \& Pos Tes.}

Pre tes yakni suatu bentuk pertanyaan, dilontarkan guru kepada muridnya sebelum memulai suatu pelajaran. Pertanyaan ditanya ialah materi yang akan diajar pada hari itu (materi baru). Pertanyaan biasanya dilakukan guru pada awal pelajaran. Pre test di maksud untuk mengetahui apakah ada diantara murid sudah mengetahui mengenai materi akan diajarkan. Pre test juga bisa di artikan sebagai kegiatan menguji tingkatan pengetahuan siswa terhadap materi akan disampaikan, 
kegiatan pre test dilakukan sebelum kegiatan pengajaran diberikan. Adapun manfaat diadakannya pre test untuk mengetahui kemampuan awal siswa mengenai pelajaran yang disampaikan. Dengan mengetahui kemampuan awal siswa, guru dapat menentukan cara penyampaian pelajaran yang akan di tempuh nanti.

Pos test, bentuk pertanyaan yang diberikan setelah pelajaran/materi telah disampaikan. Singkatnya, pos test itu evalausi akhir saat materi yang di ajarkan pada hari itu telah diberikan guru memberikan pos test dengan maksud apakah murid sudah mengerti dan memahami mengenai materi yang baru diberikan pada hari itu. Manfaat dari diadakannya pos test ini untuk memperoleh gambaran tentang kemampuan yang dicapai setelah berakhirnya penyampaian pelajaran. Hasil pos test ini dibandingkan dengan hasil pre test yang telah dilakukan sehingga diketahui seberapa jauh efek atau pengaruh pengajaran yang telah dilakukan, disamping sekaligus dapat diketahui bagian bagian mana dari bahan pengajaran yang masih belum dipahami siswa.

\subsection{Penyelesaian Masalah.}

Penyelesaian masalah yang dihadapi SMAN 4 Kota Pagar Alam, dengan melakukan pelatihan yang mana pelatihan dilakukan dengan cara disampaikan tentang teori excel, pengolahan data dengan excel, cara menjalankan excel, dan contoh-contoh logika penyelesaian pengolahan data dengan excel, selanjutnya peserta pelatihan diminta mempraktekkan seluruh teori yang telah dipahaminya dari teori, dan sambil memasukkan nilai mata pelajaran yang diampunya sehinga ketika ada masalah mereka dapat langsung bertanya dengan narasumber tentang cara penginputan data dan nilai pada excel.

\section{PEMBAHASAN DAN HASIL.}

3.1. Realisasi \& Pemecahan Masalah.

Pada penyelesaian masalah sedikit terdeskripsi realisasi dan pemecahan permasalahan pada saat pengabdian kepada masyarakat, maka lebih detai penyelesaian atau pelaksanaan pengabdian adalah sebagai berikut, terdeskripsi dalam tabel 1, berikut:

Tebel 1. Kegiatan

\begin{tabular}{|l|l|c|}
\hline \multicolumn{1}{|c|}{ Waktu } & \multicolumn{1}{|c|}{ Materi } & Penyaji \\
\hline $08.00-09.00$ & Pre Test & \\
$09.00-09.30$ & Persiapan Membuat Aplikasi pengolah data nilai & \multirow{2}{*}{ Alfis Arif } \\
\hline $09.30-12.00$ & $\begin{array}{l}\text { Panduan Membuat aplikasidan Tutorial Membuat aplikasi } \\
\text { pengolah data nilai dengan Ms. Excel }\end{array}$ & \\
$12.00-12.30$ & Ishoma & \\
$12.30-13.00$ & Post-test & \\
\hline
\end{tabular}

Berdasarkan langkah pelaksanaan pengabdian diatas (Tabel 1) melalui metode pelaksanaan yang dilakukan pada saat pengabdian (PkM) yang mana pelatihan dilakukan seperti seminar, dilakukan dengan menjelaskan materi tentang pengolahan data nilai, yang dalam hal ini pembahasan bagaimana mengedit sehingga kualitasnya makin baik dan diinginkan, yang mana struktur pelaksanaan sesuai dengan tabel (Tabel 1) diatas, didahului dengan melakukan pre tes untuk memahami tingkat pemahamaan terhadap teori dan pengolahan tentang data nilai, setelah dilakukan tes selanjutnya dilakukan persiapan pengolahan, persiapan ini melakukan pengenalan terhadap fitur-fitur Microsoft excel dan memberikan contoh bagaimana melakukan aplikasi terhadap fitur yang ada pada excel, sampai para peserta benar-benar memahaminya sepenuhnya seluruh fungsi dari fitur yang ada untuk digunakan pada saat melakukan pengolahan data nilai mata pelajaran yang diampu oleh peserta pelatihan.

Begitu seluruh peserta pelatihan memahami dan mengerti cara mengaplikasikan fitur yang ada dalam pengolahan data nilai, agar lebih baik lagi pemahaman para peserta pelatihan dalam hal ini maka selanjutnya dilakukan pendampingan pengolahan secara langsung terhadap data atau nilai yang dimiliki dengan aplikasi mengolah atau melakukan pelatihan pengolahan secara langsung, para peserta mengaplikasikan pemahamannya pada saat mengolah data nilai, dan narasumber secara langsung membimbing dan mendampingi para peserta melakukan pengolahan nilai dengan 
excel, sehingga para peserta pelatihan dengan mudah mengaplikasikan pelajaran secara langsung dan pada saat ada masalah atau kesulitan peserta langsung bertanya pada pelatih atau narasumber secara langsung, sehingga peserta benar-benar paham dan benar-benar bisa melakukan perhitungan nilai dengan menggunakan aplikasi excel untuk nilai.

Setelah dilaksanakan secara terstruktur dan terurut, pelaksanaan pengabdian dilakukan sebenarnya pengabdi sudah menyakini bahwa peserta pelatihan telah memiliki pemahaman dan pengetahuan yang sangat baik dalam mengolah nilai mata pelajaran yang diampunya, tetapi secara prosedur harus dilakukan tes lagi untuk mengetahui lebih prosedural tingkat pemahaman peserta dalam menyerap materi yang telah disampaikan maka dilakukan pos tes, hasilnya $100 \%$ peserta pelatihan memahami materi dan pelatihan edit serta mengolah nilai dengan sangat baik, yang mana pada awalnya mereka tidak memahami sama sekali tetapi metode belajar secara langsung pada aplikasi meningkatkan semangat peserta untuk belajar pengolahan data nilai dengan excel, dengan belajar secara langsung ternyata sangat mengena dengan keinginan peserta pelatihan ini.

\subsection{Pembahasan \& Hasil.}

Pengabdian yang telah dilaksanakan ini tentu telah menghasilkan banyak hal yang sangat berguna bagi objek pengabdian sehingga berdasarkan urutan pelaksanaan pengabdian yang dilaksanakan diatas yang terdeskripsi didalam tabel 1. Maka berikut ini merupakan uraian keberhasilan yang didapatkan dari pelaksanaan pengabdian (PkM) yang dilaksanakan pada SMAN 4 Kota Pagar Alam, yang mana pada pelaksanaannya peserta harus diberikan pemahaman bukan hanya aplikasi tetapi pemahaman dasar tentang excel.

Tabel 2. Keberhasilan Pelaksanaan Kegiatan

\begin{tabular}{|l|l|}
\hline \multicolumn{1}{|c|}{ Materi } & \multicolumn{1}{|c|}{ Hasil } \\
\hline $\begin{array}{l}\text { Persiapan pengolahan data, } \\
\text { menyiapkan data komponen } \\
\text { nilai }\end{array}$ & $\begin{array}{l}\text { Peserta mampu menganalisis data dan mengumpulkan data } \\
\text { yang sesuai dengan kebutuhan untuk diolah menggunakan } \\
\text { excel }\end{array}$ \\
\hline $\begin{array}{l}\text { Pengenalan fitur dan tools yang } \\
\text { ada pada excel }\end{array}$ & $\begin{array}{l}\text { Para peserta mampu memahami dan mengetahui tools dan } \\
\text { fitur yang ada pada excel, logika perintah dan perhitungan } \\
\text { logis pada excel. }\end{array}$ \\
\hline $\begin{array}{l}\text { Menunjukan contoh mengolah } \\
\text { data nilai }\end{array}$ & $\begin{array}{l}\text { Hasilnya peserta pelatihan mengetahui dan memanfaatkan } \\
\text { tools aplikasi excel dengan baik dengan melihat contoh. }\end{array}$ \\
\hline Membuat latihan dengan excel & Peserta pelatihan mampu mengolah data nilai dengan excel. \\
\hline
\end{tabular}

Melalui tabel 2, di sini bisa di pahami hasil dari kegiatan pengabdian (PkM) yang dilakukan ini softskills para peserta yang mengikuti pelatihan meningkat dengan sangat baik dan pelatihan berhasil dengan sangat baik, sehingga peserta pelatihan menjadi lebih optimis dalam menghadapi masa depannya ini memberikan keuntungan bagi SMAN 4 Kota Pagar Alam karena masyarakat semakin percaya dan bagi STTP dengan pengabdian dan pelatihan ini menjadi tempat untuk berbagi pengetahuan dan keilmuan yang diperoleh dari penelitian dan pendidikan, sehingga bisa diidentifikasi berikut merupakan hasil akhirnya, yaitu:

a. Para peserta pelatihan guru SMAN 4 Kota Pagar Alam mempunyai pengetahuan dan pemahaman yang baik tentang pengolahan nilai menggunakan excel untuk mengolah data nilai mata pelajaran yang diampu.

b. Seluruh peserta guru SMAN 4 Kota Pagar Alam menjadi sangat paham terhadap teknologi informasi yang lebih aplikatif untuk mendukung dalam pengolahan data yang diperlukannya seperti data nilai ini.

c. Para guru SMAN 4 Kota Pagar Alam sudah terbantu dalam pemberian pemahaman terhadap teknologi informasi up to date yang cukup aplikatif. 


\section{KESIMPULAN}

Dalam pelaksanaan pengabdian masyarakat $(\mathrm{PkM})$ ini yang dilakukan di SMAN 4 Kota Pagar Alam dengan tujuan melatih Guru dalam melakukan pengolahan terhadap data nilai menggunakan excel, didapatkan kesimpulan sebagai berikut:

a. Proses pembelajaran dengan cara belajar aplikasi secara langsung ternyata sudah mampu meningkatkan semangat belajar menjadi lebih baik, contoh dalam mengolah nilai ini.

b. Menambah softskills para Guru SMA 2 Kota Pagar Alam dalam bidang pengolahan data menggunakan excel ini.

c. Meningkatkan rasa percaya diri dengan kemampuan yang tentu sangat banyak sekali.

d. Membantu guru pelajaran TIK dalam hal memahamkan guru lain terhadap suatu aplikasi tertentu dalam hal ini pengolahan data nilai dengan excel.

\section{SARAN}

Maka berdasarkan pengalaman yang dilihat dan dirasakan penulis saat melakukan pengabdian ini maka, penulis dalam hal ini bisa memberikan saran:

a. Penambahan waktu pelatihan

b. Program kerja lebih jelas.

\section{UCAPAN TERIMA KASIH}

Penulis mengucapkan terima kasih kepada Panitia KKN dan Pengabdian bagi Dosen, terima kasih kepada keluarga, kawan-kawan dosen.

\section{DAFTAR PUSTAKA}

[1] M.H Jogiyanto, 1995, Pengenalan Komputer, Andi Offset Yogyakarta.

[2] Horsley, M., Knight, B., \& Huntly, H. 2010. The role of textbooks and other teaching and learning resources in higher education in Australia: Change and continuity in supporting learning. IARTEM 1-Journal. 3(2). 43-61.

[3] Muslim, B. 2018. Pelatihan aplikasi editing video dengan filmora., Laporan Pengabdian Kepada Masyarakat, LPPM STT Pagaralam.

[4] Muslim, B. 2018. Pelatihan Pembuatan Blog Bagi Guru Ma Ponpes Darul Mutaqin Kota Pagaralam. NGABDIMAS. Vol 1. No.1. Bulan Juni, Hal. 6-11

[5] B. Muslim, Pengantar teknologi informasi. Yogyakarta: Deepublish, 2017.

[6] Muslim, B. (2018). Analisis system informasi (SI) terintegrasi di Perguruan Tinggi (PT) (Studi Kasus: STT Pagaralam). Jurnal Teknologi Informasi MURA, Vol 10. Page 83-91.

[7] Muslim, B (2014). Analisis rencana aplikasi teknologi informasi pada STT Pagar Alam. Proseding semnastik dan Magma. Issue: Aplikasi Teknologi dan sistem Informasi. PPP UBD Pres. Pages 397-404.

[8] Hutchinson E. Sarah and Sawyer C. Stacey, 2000, Computers, Communications \& Information, McGraw Hill Companies Inc.

[9] Indonesia Services Education HP Tim, 2001, Manajemen Sistem Belajar Di Dunia Maya, Majalah Info Komputer.

[10] Sadiman, A.S., Rahardjo, R., Haryono, A., \& Rahardjito. 2006. Media pendidikan: Pengertian, pengembangan, dan pemanfaatan. Jakarta: Rajagrafindo Persada.

[11] Menristekdikti. 2016. Panduan Pelaksanaan Penelitian dan Pengabdian Masyarakat di Perguruan Tinggi Edisi X Tahun 2016. hlm. 4

[12] Isro'Mukti, Y. (2017). Sistem Informasi Madrasah Aliyah Negeri Pagar Alam Berbasis Web. Indonesian Journal of Computer Science, 6(2), 192-205.

[13] Mukti, Y. (2017). Perencanaan Strategis Sistem Informasi Dan Teknologi Informasi Pada Sekolah Menengah Kejuruan Negeri 2 Pagar Alam. JURNAL ILMIAH BETRIK: Besemah Teknologi Informasi dan Komputer, 8(02), 83-92.

[14] Arif, A., \& Mukti, Y. (2017). Rancang Bangun Website Sekolah Menengah Pertama (SMP) Negeri 8 Kota Pagar Alam. JURNAL ILMIAH BETRIK: Besemah Teknologi Informasi dan Komputer, 8(03), 156-165.

[15] Isro'Mukti, Y. (2018, October). Sistem Informasi Manajemen Aset Sekolah Tinggi Teknologi Pagaralam Berbasis Web. In Seminar Nasional Teknologi Informasi dan 
Komunikasi (SEMNASTIK) (Vol. 1, No. 1, pp. 632-638).

[16] Mukti, Y. (2018). Rancang Bangun Website Sekolah Dengan Metode User Centered Design (UCD). JURNAL ILMIAH BETRIK: Besemah Teknologi Informasi dan Komputer, 9(02), 84-95.

[17] Mukti, Y. (2018). Pelatihan Maintance Komputer SMAN Pagar Gunung. NGABDIMAS, $1(1), 47-51$.

[18] Mukti, Y. I. (2019). Implementasi Jaringan Hotspot Kampus Menggunakan Router Mikrotik. Indonesian Journal of Computer Science, 8(2), 130-138.

[19] Mukti, Y. I., \& Puspita, D. (2019). Sistem Informasi Peringatan Dini Bencana Pada Kota Pagar Alam Berbasis Mobile. Jusikom: Jurnal Sistem Komputer Musirawas, 4(2), 65-74.

[20] Mukti, Y. I. (2019). SISTEM INFORMASI MONITORING KESEHATAN MASYARAKAT BERBASIS WEB MENGGUNAKAN METODE UNIFED MODELLING LANGUAGE. Jusikom: Jurnal Sistem Komputer Musirawas, 4(1), 1-8.

[21] Mukti, Y. I., \& Puspita, D. (2019, December). Web Based Disaster Early Warning System on Pagar Alam City. In Conference SENATIK STT Adisutjipto Yogyakarta (Vol. 5, pp. 309-316).

[22] Isro'Mukti, Y., \& Puspita, D. WEB BASED DISASTER EARLY WARNING SYSTEM ON PAGAR ALAM CITY.

[23] Puspita, D., \& Isro'Mukti, Y. (2019, December). Web-Based Culture Information System of Literature Besemah City of Pagar Alam. In Conference SENATIK STT Adisutjipto Yogyakarta (Vol. 5, pp. 303-308). 